\title{
"O comprimido entra e o chip sai": uma análise etnográfica da medicalização da periculosidade em um manicômio judiciário
}

TÚLIO MAIA FRANCO

\section{Introdução}

Este trabalho pretende contribuir para os estudos da "medicalização da periculosidade" (Mitjavila e Mathes 2016; Mitjavila e Vásquez 2018) a partir de um relato etnográfico que resulta de uma investigação anterior (Franco 2017) a qual empreendi para minha dissertação de mestrado. Nesta pesquisa realizei uma etnografia sobre o "tratamento-compulsório" oferecido aos internos de um Hospital de Custódia e Tratamento Psiquiátrico (HCTP) no Estado do Rio de Janeiro.

Para compreendermos a expressão "medicalização da periculosidade" precisamos entender, primeiramente, o que chamamos de "medicalização", qual seja: o "conjunto de processos caracterizados pela expansão do campo de objetos de conhecimento e de intervenção da medici $\neg$ na científico-técnica" (Mitjavila e Mathes 2016:848). No caso específico da "medicalização da periculosidade", trata-se da conversão do crime "em objeto do saber e da prática médica" (idem), tornando-o "parte dos processos mais amplos de medicalização da vida social que organizaram a experiência da modernidade por meio de diversas estratégias biopolíticas" (idem). Neste texto pretendo colocar em detalhes de que maneiras essas "estratégias biopolíticas" são encarnadas e performadas por agentes particulares, bem como pretendo demonstrar como a "medicalização da periculosidade", i.e. a incorporação do domínio do crime pelo regime médico, também pode ser lida de maneira ainda mais literal, ou seja, procuro analisar a forma pela qual a "periculosidade" é medicalizada e, portanto, inscrita em um regime de "tratamento", na medida de segurança, que é profundamente farmacocêntrico. 
Inserida no regime psiquiátrico a "periculosidade" ganha um vínculo manifesto com o transtorno mental do indivíduo (Mitjavila e Mathes 2016). Esta associação entre "transtorno mental" e "periculosidade" acarreta na noção de que o cometimento do crime tem raízes psicopatológicas e pode ser tratado, sobretudo, farmacologicamente. $\mathrm{O}$ profundo laço entre a etiologia psiquiátrica hegemônica e a indústria farmacêutica (Rose 2013; Iriart e Merhy 2017) é instituído a partir da reiteração performática entre o complexo terapêutico e o "doente mental" como seu objeto e consumidor final. A partir deste entrelaçamento não seria mais possível estabelecer tão nitidamente se é a elaboração dos novos medicamentos que produzem novos transtornos mentais ou o contrário (Leader 2015).

Já é algo estabelecido na literatura especializada o papel da moral para a construção da carreira e subsequente rotulação de determinados desviantes como "loucos" (Goffman 1974). No caso especifico do HCTP, entretanto, é preciso notar o modo particular que se relacionam as moralidades em jogo e a codificação estatal. Como narra Michel Misse (2010:22): "O crime é definido primeiramente no plano das moralidades que se tornaram hegemônicas e cuja vitória será inscrita posteriormente nos códigos jurídicos”. A valoração moral do crime cometido pelo réu que ao longo do processo penal e/ou na sua execução foi declarado "inteiramente incapaz de entender o caráter ilícito do fato [do crime] ou de determinar-se de acordo com esse entendimento" (Brasil 1984:art. 26) será diferenciada. Nos casos de inimputabilidade ou semi-imputabilidade do acusado ocorre a substituição jurídica de sua pena pelo cumprimento da medida de segurança ${ }^{1}$. Este deslocamento implica na substituição da chamada pena privativa de liberdade (cumprida na "prisão comum") pelo tratamento em âmbito ambulatorial ou a internação em um HCTP, mais conhecido como manicômio judiciário.

Durante a medida de segurança o interno deve se submeter periodicamente aos chamados "exames de cessação de periculosidade", nos quais o perito-psiquiatra responsável pelo seu caso deve emitir, resumidamente, um parecer dizendo se ele ainda representa ou não "perigo para si ou para outrem"2. O tempo em que um manicomializado passa na instituição pode ser maior do que se ele fosse condenado pelo mesmo crime na prisão comum. Ao contrário do "preso comum", aquele que é declarado louco acaba não tendo as mesmas garantias legais, já que a decisão da desinternação ou não do paciente não é determinada pelo rito mais ou menos regular da burocracia da execução penal, fixada pelo Código Penal, cuja progressão do tempo de prisão normalmente significa alívio no regime prisional. No manicômio judiciário a manutenção do "condenado" ${ }^{3}$ no hospital-prisão passa necessariamente pela decisão psiquiátrica que pode ser ou não confirmada pelo juiz (Peres e Nery Filho 2002).

A significativa produção de exames e perícias no sistema penal não estão restritas aos casos dos internados nos manicômios judiciários. Até mesmo o "preso comum”, que cumpre sua pena em uma unidade convencional, tem que passar por uma série de avaliações de psicólogos, psiquiatras e assistentes

1 Há também os casos em que em alguns processos penais o interno responde como "são" e em outros como “insano", nesses casos há a possibilidade de conversão dos pedidos de medida de segurança em "pena comum" e vice-versa.

2 Critério este que justificaria qualquer internação psiquiátrica.

3 Ainda que juridicamente a expressão "condenado" não faça sentido ao se referenciar ao preso em medida de segurança, pois tecnicamente ele não é responsável criminalmente pelo ato que cometeu e, portanto, não poderia ser condenado penalmente pelo crime. Mesmo assim, eu utilizo este termo, pois para muitos dos atores que encontrei no campo (funcionários e pacientes) a medida de segurança é experimentada tanto como pena, quanto tratamento e o manicômio judiciário, como prisão. 
sociais nos chamados "exames criminológicos” para que consigam os benefícios em relação à sua pena. No entanto, no caso dos HCTP, com a conversão da pena em tratamento, os diferentes exames multidisciplinares e, principalmente, o psiquiátrico ganham ainda mais relevância. Essa centralidade se dá pelo fato destes exames serem capazes de revelar qual a probabilidade do paciente, quando desinternado, voltar a delinquir e, assim, dependendo do diagnóstico, definir se o preso estaria habilitado ou não para sua desinternação.

Os medicamentos, em contrapartida, surgem em uma dupla implicação no tratamento-compulsório da medida de segurança, tanto como mecanismos disciplinares, quanto de "tecnologias de si" (Foucault $\left.1988^{4}\right)$. Servem para conter a "periculosidade" dentro do perigoso, mas também para converter o “criminoso" em "doente mental”, sujeitá-lo e tratá-lo.

Antes de prosseguirmos com o desenvolvimento do artigo algumas considerações metodológicas são necessárias. As descrições etnográficas aqui apresentadas se concentrem maciçamente em um dos dois HCTP existentes no Estado do Rio de Janeiro. Eu entrevistei familiares e examinei documentos de ambos manicômios. Entretanto, apesar de existirem algumas diferenças: o HCTP em que foi realizada a etnografia não comporta tantos presos provisórios e pacientes internados pelo uso crônico de drogas, quanto (de acordo com informações oferecidas pelos próprios atores) o outro manicômio, não acredito que haja uma grande divergência na natureza dos fenômenos que ocorrem nas duas instituições. A diferença mais significante é a de que enquanto o HCTP não etnografado abriga pacientes mulheres, o estabelecimento estudado é exclusivamente masculino. Embora eu tenha acompanhado alguns atendimentos feitos no HCTP que tem uma ala feminina não acredito ter construído volume suficiente de dados que pudessem ser criteriosamente analisados e por isso estes não serão aqui tratados.

Os nomes de todos aqueles e aquelas que ilustram as páginas deste artigo são fictícios. Todas as entrevistas foram concedidas mediante a assinatura do entrevistador e entrevistado do "Termo de Consentimento Livre e Esclarecido". O projeto para a realização desta pesquisa foi aprovado no dia 13 de abril de 2016 pelo Comitê de Ética competente, qual seja: CFCH - Centro de Filosofia e Ciências Humanas da UFRJ. A realização desta pesquisa também contou com a autorização da Defensoria Pública do Estado do Rio de Janeiro, sem a qual este trabalho não seria possível.

\section{Nas veias do manicômio: abrindo a caixa da "estabilização psiquiátrica”}

"Isso aqui é o S.U.S. ${ }^{5}$ do S.U.S. da p.q.p.!" (Funcionária). Essa foi uma das primeiras frases que escutei quando adentrei pela primeira vez à sala da equipe técnica do primeiro Hospital de Custódia e Tratamento Psiquiátrico (HCTP) que conheci.

\footnotetext{
4 Neste artigo todas as traduções de textos estrangeiros não publicados em português foram feitas por mim, eventuais erros de tradução, portanto, são de minha exclusiva responsabilidade.

5 Sistema Único de Saúde.
} 
Estava acompanhado por Ana, analista recém-admitida pela Defensoria Pública do Estado do Rio de Janeiro, depois de apertarmos a campainha do lado de fora do HCTP, nós fomos recebidos pelo Sr. Adalto, agente penitenciário que cuidava do acesso ao hospital-prisão. Adalto era responsável por fazer a guarda da entrada e saída do edifício e a inspeção dos veículos que adentravam os pesados portões de ferro do manicômio judiciário. Com o funcionário todos que entravam, nós inclusive, deixávamos os telefones celulares. Ele, por sua vez, os depositava em um escaninho na guarita, nos entregando um pedaço de papel com o número correspondente ao local em que deixamos os aparelhos.

Quando o restante da equipe chegou nós demos prosseguimento à entrada de fato no HCTP, registramos nossos nomes e os horários em que chegamos no "livro da Defensoria". Passamos pelo pátio da entrada em frente ao primeiro edifício, onde funcionava o centro administrativo do manicômio e o auditório, e avançamos em direção ao segundo edifício. Entramos nele através de uma porta gradeada que nos foi aberta por outro agente penitenciário. Viramos à direita, percorremos um corredor e entramos na sala da equipe técnica também à direita.

Neste dia em específico, as funcionárias do hospital que acompanhariam o atendimento jurídico (realizado pela defensora pública, seus estagiários e a analista) comentavam, como se denota da frase citada anteriormente, o quanto as condições de seu trabalho eram precárias. Essa precariedade, naquele contexto, era justificada pela crise orçamentária em que o Estado se encontrava, pois, por causa dela, não se havia suprido regularmente o estoque de medicamentos do manicômio, assim como o salário das servidoras estava atrasado.

À falta de medicamentos fornecidos pelo Estado era atribuída a crise subjetiva dos pacientes: " $o s$ pacientes estão indo surtados para as audiências!", exclamava uma trabalhadora. Isso trazia uma maior dificuldade para a gestão dos internos, como disse uma servidora: "o médico surtou", pois os pacientes estavam sem Haldol ${ }^{\circledR}{ }^{6}$. Não só este manicômio judiciário, HCTP-X, mas a outra instituição em funcionamento também estava na mesma situação (HCTP-Z).

A crise do Estado confundia-se com a crise psiquiátrica dos pacientes e o "surto" dos funcionários. Os medicamentos aparentavam estabilizar todo "circuito de afetos" (Safatle 2015) que corria no sistema nervoso do manicômio. A viva e angustiada agitação dos pacientes era percebida como um distúrbio institucional. De imediato a defensora pública, responsável juridicamente pelos pacientes internados, articulou uma série de procedimentos jurídicos para que o Estado suprisse a demanda por medicamentos. Esses procedimentos produziram dois ofícios para a Defensoria Pública: um para a coordenadora de saúde e tutela coletiva e outro para o coordenador do Núcleo do Sistema Penitenciário. Nesses ofícios a defensora destacou:

É importante ressaltar que a falta de medicamento aos pacientes do HCTP-Z repercute negativamente em seus tratamentos, uma vez que acarreta a alteração em seus comportamentos, com consequente aumento no número de intercorrências que se caracterizam por surtos psicóticos, crises de ansiedade, insônia, auto e heteroagressividade. (Ofício Interno, Defensoria)

6 Medicamento antipsicótico, também conhecido pelos trabalhadores do HCTP como “injeção S.O.S.” 
Após essa notificação institucional, a defensora mandou um novo ofício para a direção do próprio HCTP. Neste documento foi enfatizado que os pacientes "durante o atendimento jurídico se mostravam muito agitados, sendo certo que diversos deles reclamavam da falta de medicamentos". No ofício foram requeridas quatro informações: 1) a "listagem dos medicamentos solicitados pela Farmácia" do HCTP à Divisão de Insumos da Secretaria Estadual de Administração Penintenciária (SEAP); 2) "listagem dos medicamentos fornecidos" pela SEAP; 3) "sobre a forma como tem sido tratados os pacientes psiquiátricos internados nesse HCTP, na ausência de possibilidade material de efetivar a prescrição médica, descrevendo o impacto para os pacientes de emergência psiquiátrica e os demais"; 4) para que informe sobre as consequências da "falta de medicamentos" e como ela "interfere na convivência dos pacientes entre si e na sua relação com os servidores".

Em relação aos dois últimos itens, respondeu a direção:

3- Os pacientes são frequentemente avaliados pelos médicos assistentes, sendo certo que a descontinuidade no uso dos medicamentos prescritos influencia negativamente no comportamento dos pacientes, dificultando muitas vezes a abordagem dos demais técnicos e consequentemente o tratamento psicoterápico de que necessitam. Nesse sentido tem sido feito um esforço dos médicos para adequarem suas prescrições aos medicamentos disponíveis em nossos estoques de maneira a garantir minimamente o tratamento dos pacientes, bem como contamos com a colaboração dos familiares dos pacientes em conseguir na rede de saúde mental os medicamentos prescritos, nos casos em que não são possíveis as substituições. 4 - a descontinuidade no uso dos medicamentos prescritos tem como principal consequência o aumento no número de intercorrências que se caracterizam por surtos psicóticos, crises de ansiedade, insônia e de auto e heteroagressividade. (Ofício, Direção do HCTP-Z)

A este documento a direção anexou também o relatório da fiscalização feita pelo Ministério Público sobre o fornecimento de psicotrópicos à instituição. Um destes documentos apontou para o

transtorno que está causando a falta de medicamentos nesta Unidade, medicamentos estes imprescindíveis ao funcionamento de qualquer hospital psiquiátrico, tais como; Haloperidol, Biperideno, Carbamacepina, Fenitoína, Fenobarbital, Fluoxetina, Levomepromazina, Clorpromazina, Clonazepan, Diazepan [...] O não fornecimento destes medicamento [sic] certamente causa sérios problemas aos pacientes e à rotina desta Unidade Hospitalar. (Idem)

Em outro documento a promotora relatou ao Secretário de Estado de Administração Penitenciária que "a falta de medicação tem sido sentida pelos pacientes, que têm entrado em surto com mais frequências".

Resumidamente, da análise destes documentos podemos concluir que a falta de medicamentos no manicômio judiciário é percebida por múltiplos ângulos: a) como um dano ao tratamento, ela torna o corpo do paciente menos acessível às tecnologias terapêuticas, causa uma repercussão "negativa no tratamento", dificultam "a abordagem dos demais técnicos e consequentemente o tratamento psiquiátrico que [os pacientes] necessitam"; b) como uma "alteração no comportamento" que "influencia negativamente no comportamento dos pacientes" e geram um "aumento no número" de "surtos psicóticos, crises de ansiedade, 
insônia”; c) como uma forma de desequilíbrio no sistema disciplinar, a falta de medicamentos geraria um descontrole dos próprios internos que os exporia ao perigo de si mesmos, mas também exporia ao risco os funcionários. De forma geral, a falta de medicamentos aumentaria a incidência de "auto e heteroagressividade".

Embora ao remédio fosse atribuída a capacidade de contornar os "surtos psicóticos, crises de ansiedade, insônia” dos pacientes, nós não podemos designar esses fenômenos como simples manifestações do "transtorno mental" dos internos. Ao contrário, esses efeitos podem ocorrer pelo próprio agenciamento que o psicotrópico exerce, pela sua ausência, no organismo em abstinência, como destaca o pesquisador e médico dinamarquês Peter Gøtzsche (2016:265):

Os antipsicóticos diminuem as concentrações de dopamina, e o número de receptores de dopamina aumenta para compensá-los. Se deixamos repentinamente de tomá-los, a resposta do cérebro pode ser em forma de psicose, um fenômeno conhecido como tolerância oposta ou psicose por supersensibilidade.

No entanto, esse efeito não é exclusivo à interrupção do medicamento: “Também é possível apresentar um episódio psicótico durante o tratamento continuado, e [o paciente] pode não responder ao aumento das doses" (Idem). O uso dos psicotrópicos pelos pacientes psiquiátricos tecem um emaranhado vital entre coisas e pessoas, sendo especialmente difícil, senão impossível, separar o que é próprio da pessoa do que seria exclusivo da "coisa" (Ingold 2012).

$\mathrm{Na}$ cena etnográfica acima o corpo institucional e o corpo dos internos parecem fazer parte de um mesmo "circuito de afetos" (Safatle 2015). Se a falta do medicamento traz "sérios problemas aos pacientes e à rotina" da "Unidade Hospitalar" é porque com sua presença essa rotina flui melhor. Interessante notarmos que é também a partir da falta dos medicamentos que nós podemos perceber a criatividade de que se vale a direção do HCTP para supri-la. A direção não está encerrada em si mesma: por um lado foi preciso acionar as redes informais de abastecimento do estoque químico do manicômio: "os familiares que conseguem os medicamentos na rede de saúde mental". Por outro, foi necessário improvisar com certos medicamentos para que alguns suprissem a ausência de outros: a falta de medicamentos dá lugar à alquimia dos psiquiatras.

Os psicotrópicos, nesta perspectiva, surgem como um mecanismo disciplinar capaz de "intervir no nível do que acontece, no momento em que a virtualidade está se tornando realidade [...] [esse mecanismo] tende a intervir previamente, antes até do próprio ato, se possível” (Foucault 2006: 63-64). Os remédios seriam capazes de conter o comportamento no nível dos corpos e assegurar a rotina institucional.

No manicômio judiciário os medicamentos têm uma relação íntima com os corpos dos internos. Uma folha pregada no mural da sala de reuniões deixava claro esta relação tão estreita entre o medicamento e a gestão dos corpos na instituição :

À Equipe Técnica,

Considerando o número reduzido de ISAP’s [Inspetores de Segurança e Administração Penitenciária], plantonistas nas turmas, a falta de psicotrópicos e o impacto destas carências sobre os 
pacientes desta Unidade, solicito que V.S.a que conscientize as estagiárias de sua equipe quanto ao risco de entrar na SEAP-[X] vestindo roupas decotadas, calças justas, vestidos transparentes, saias curtas e quaisquer outras vestimentas do gênero.

\section{[Nome Completo] \\ Diretora SEAP-[X] \\ ID - 0000}

A diretora ao descrever tanto as "estagiárias", quanto os "pacientes" parece hipersexualizá-los e atribui, além de um défucit institucional, à falta de medicamentos uma possível agressão de cunho sexual dos pacientes às estagiárias. A descrição da diretora nos indica que um significativo efeito colateral dos medicamentos, mas não menos providencial, é a diminuição considerável do desejo sexual ( Jenkins 2011; Gøtzsche 2016). Garantir o “equilíbrio psiquiátrico” dos pacientes é também, segundo a diretora, conter uma das fontes do perigo oferecido pelos internos ao corpo institucional: sua sexualidade.

A “estabilização psiquiátrica” dos internos é central à instituição. Nós podemos considerá-la o primeiro passo necessário para o engajamento do interno no tratamento-compulsório, neste momento, ao aceitar o consumo de psicotrópicos, o paciente reconheceria sua doença e manifestaria, para os funcionários do HCTP, o desejo de ser tratado. Cabe notar que ao dever de atingir uma "estabilidade psiquiátrica" está pressuposta uma "instabilidade bioquímica" a ser atacada, é a partir desta noção biomédica que se toma como necessária a intervenção farmacológica (Jenkins 2011:35).

A questão mais crítica a respeito da, poderíamos afirmar sem nenhum exagero, ideologia do "equilíbrio químico" do tratamento farmacológico é que não foi adequadamente comprovada a ligação estreita de um "transtorno mental" com o aumento ou diminuição da taxa de qualquer substância corporal específica. Como argumenta Peter Gøtzsche (2016:283, grifo no original):

Por exemplo, a ideia de que as pessoas depressivas têm uma carência de serotonina tem sido claramente rechaçada. Alguns fármacos que diminuem a serotonina também parecem funcionar para a depressão, por exemplo a tianeptina.

Uma pesquisa realizada na Dinamarca pelo psiquiatra Lars Vedel Kessling e outros colegas (2005:1208) com 493 pacientes pode nos oferecer alguns insights a este respeito. 80,2\% dos pacientes que responderam aos questionários concordavam com a afirmação: "antidepressivos corrigem as mudanças que ocorrem no meu cérebro devido ao estresse ou problemas" (idem). Desta mesma amostra 58,1\% discordavam da frase: "Meus problemas emocionais são resolvidos pelos antidepressivos" (idem) e 74,6\% concordavam que "Antidepressivos me fortalecem para que eu esteja habilitado a lidar de maneira mais eficaz com os meus problemas" (idem). A discrepância entre a crença no "equilíbrio químico" (80,2\%) e a discordância da eficácia do medicamento em "resolver" os problemas emocionais $(58,1 \%)$, aponta que, para os pacientes consultados, o papel do fármaco é mais o de garantir uma melhor performance do indivíduo, habilitando-o a "lidar de maneira mais eficaz com" (idem) seus problemas, do que de tratar a 
causa do "transtorno mental". Segundo essa versão os medicamentos parecem se comportar mais como mediadores técnicos (Latour 1994) das emoções do que do "transtorno mental" em si.

Do grupo de pacientes desta pesquisa $81,5 \%$ concordavam que "Desde que você esteja tomando antidepressivos você não sabe realmente se eles são de fato necessários" (idem). A partir dessa informação podemos pensar que, no sentido contrário, os pacientes só se dão conta da necessidade dos medicamentos assim que tentam parar de tomá-los. Todavia, como aponta Gøtzsche (2016:284) assim que os pacientes "tentam deixar o tratamento, [eles] sofrem sintomas de abstinência, mas os médicos insistem [em dizer] de que se trata de uma recaída” da doença.

A dificuldade em separar os efeitos dos medicamentos no organismo com os efeitos da "doença" na relação psicotrópicos-tratamento-paciente é um obstáculo que coloca em xeque a tese do "equilíbrio químico", pela qual existiria uma correlação imediata entre medicamento, regulação corporal e estabilização do transtorno mental. Os medicamentos mais parecem mediar a relação do organismo com o ambiente do que atuar na causa do distúrbio orgânico. Entretanto a ideologia do equilíbrio químico nos diz exatamente o oposto: que o medicamento atua sobre a doença normalizando uma função individual do organismo, a função psíquica neste caso, que está desregulada. Entretanto, como afirma Vladimir Safatle (2015:426) "Quando classificamos como patológico um sistema ou um mecanismo funcional isolado", tal qual faz a psiquiatria hegemônica, "esquecemos que aquilo que os torna patológicos é a relação de inserção na totalidade indivisível de um comportamento individual." (idem). Nesse sentido, os "fatores são normal e patológico no interior de uma relação entre organismo e meio ambiente" (idem, grifos do autor) e não isoladamente.

\section{Cena I: “o comprimido entra e o chip sai!"}

Certa vez entrou um paciente na sala de reuniões para ser atendido. A psicóloga da equipe responsável pelo seu caso quando o viu comentou: "o Lucas quando tá medicado fica bem, mas ele não entende que é o medicamento que faz isso". Este rapaz em um atendimento anterior, no qual a equipe técnica havia reclamado do déficit no estoque de medicamentos da instituição, brigou com outro interno e entrou em conflito com a defensora que, por sua vez, intermediou a disputa entre os dois rapazes. É ela mesma quem comentou a resposta da funcionária: "olha eu não estudei nada disso que a Maria Estela estudou, eu que estudei direito estou vendo: uma coisa é o Lucas com remédio e outra coisa éo Lucas sem remédio... Quando ele esteve aqui [da última vez] ele zoou o Gregório [e] disse que iria me matar..." Interrompeu prontamente Lucas: “Não, não! Me desculpa..., ela: “[está] tudo desculpado!”.

Ao medicamento é atribuída uma enorme eficácia em normalizar o comportamento do usuário, como resumiu a psicóloga de um paciente cujo relato era de que a vizinha tinha lhe colocado um chip na cabeça e, por isso, ele teria incendiado o portão da residência dela: “o comprimido entra e o chip sai!”.

Uma outra cena ilustra o modo ambíguo em que o medicamento é experimentado pelos pacientes neste contexto etnográfico. No fim de um atendimento, quando indicaram a um interno que ele passaria a ser acompanhado, em regime ambulatorial, por um CAPS (Centro de Atenção Psicossocial) que ele já conhecia, o interno respondeu: " $Y$ não!' Lá dá muito remédio, fico maluco, me dão muito remédio [...] 
quando eu vou, eu tomo muito remédio, eu fico bem, mas eu passo do dia". Ao analisar os efeitos dos psicotrópicos legalizados, é impossível nos desvencilhar do caráter ambíguo do medicamento, ao mesmo tempo em que o interno identifica a hipermedicalização de si, o psicotrópico lhe faz bem. Com a droga, ele diz: "fico maluco", mas "fico bem".

Na próxima seção pretendo focar nestas relações de controle-cuidado do paciente que circunscrevem a prática da medicalização no HCTP.

\section{A construção sociotécnica da "periculosidade"}

Nesta seção destacarei com mais veemência o caso de um paciente em particular, especialmente os períodos de sua primeira internação e sua posterior reinternação no HCTP. Acredito que relatar as diferentes questões envolvidas em um caso "nos ajuda a capturar a lógica das infra-estruturas cotidianas que fazem com que certas vidas ganhem formas e outras sejam impossibilitadas" (Biehl 2008:416).

\section{a) Cena II: A internação de Sérgio}

Em março de 2016, o primeiro atendimento jurídico dentro do manicômio que eu acompanhei foi o do Sérgio, um homem, à época, de 37 anos que foi internado no HCTP-X em abril de 2014 para o cumprimento da medida de segurança. Sérgio foi acusado de ter cometido os crimes de tentativa de homicídio e dano ao patrimônio.

No relato fornecido pelo Ministério Público na denúncia crimina ${ }^{8}$ consta que Sérgio, em uma manhã da primeira semana de novembro de 2012, agrediu um pai e seu filho a golpes de facão. Neste relato, o filho teria protegido seu pai que em seguida expulsou Sérgio com "um pau para afastar o acusado do local, impedindo assim que o acusado consumasse o crime e [que o pai] recebesse atendimento médico." (Ministério Público, Processo Penal de Sérgio). Por fim, o então paciente teria golpeado o veículo de um dos homens, assim como incendiado o automóvel.

No final de março de 2014 aconteceu a audiência de julgamento de Sérgio. Ouvidos os depoimentos das vítimas e da mãe de Sérgio, apresentados os laudos do veículo, da arma utilizada e do psiquiatra" o qual declarava que Sérgio "ao tempo do fato era inteiramente incapaz em razão de doença mental", restavam comprovados o cometimento do crime e a inimputabilidade de seu autor.

Sendo Sérgio inimputável ao Juiz caberia a aplicação da medida de segurança em uma de suas modalidades: tratamento ambulatorial ou internação em um HCTP, decisão esta que seria justificada pelo menor ou maior grau de periculosidade do acusado. Como narrou o Juiz em sua sentença:

\footnotetext{
8 Peça de acusação confeccionada pelo Ministério Público que produz a versão estatal e acusatória do fato narrado, denunciando, como o próprio nome diz, seu caráter ilícito.

9 Coloco propositalmente o laudo psiquiátrico simetricamente ao lado dos demais laudos técnicos, pois todos estes documentos partilham de uma objetividade pressuposta conferida por uma epistemologia invisível, cujo testemunho é capaz de extrair da natureza uma verdade técnica dificilmente questionável (Haraway 1997).
} 
Embora o laudo [...] sugira tratamento psiquiátrico ambulatorial, evidente que o juiz não está adstrito ao laudo, sobretudo se este laudo, no caso da medida adequada não reflete a realidade atual, impondo-se, nesse momento, a observância do artigo 182 do $\mathrm{CPP}^{10}$, aplicando-se a imediata medida de internação ao acusado.

Resultando, por fim, na sentença de aplicação da medida de segurança na modalidade de internação manicomial. Esta decisão estabeleceu o prazo "por tempo indeterminado, perdurando enquanto não for averiguada, mediante perícia médica, a cessação de periculosidade, fixando o prazo minimo legal, qual seja um ano" (Juiz, Processo Criminal). Visto que

diante do seu quadro psicológico atestado pelo laudo que indica a ocorrência de surtos que levam ao acusado à conduta de extrema periculosidade independente da vítima, conforme sugerido pelo Ministério Público e pela Defesa, com base nos depoimentos das vítimas e da mãe do acusado. (Idem).

É importante notar de que forma, legalmente, a perícia psiquiátrica pode dar lugar à decisão autônoma do juiz. Conforme a sentença o magistrado havia dado conta que o laudo psiquiátrico não condizia com a "realidade atual" do acusado, realidade essa concebida pelo juiz enquanto este confeccionava a sentença. Ainda quando destitui o parecer do perito psiquiatra, o magistrado o fez também na condição de perito, condição esta em que sua subjetividade é objetividade (Haraway 1997:24). Ou seja, sua avaliação moral sobre os "surtos que levam o acusado à conduta de extrema periculosidade independente da vítima" materializa-se em uma sentença que reconduz a verdade produzida pelo laudo psiquiátrico ao atribuir a Sérgio um maior nível de periculosidade do que atribuído anteriormente pelo psiquiatra.

O laudo psiquiátrico, por sua vez, é capaz de testemunhar que "ao tempo do fato" Sérgio era incapaz de autodeterminar-se e/ou determinar o caráter ilícito do fato que havia cometido. Ou seja, o perito, através do exame psiquiátrico, é capaz de perceber atualmente, através de uma retroficção, se a periculosidade estava presente no corpo de Sérgio na época dos fatos e se ainda se encontra nele encarnada (se ele ainda é perigoso). Por "periculosidade", os peritos psiquiatras que entrevistei compreendiam a "probabilidade" do acusado/interno voltar a delinquir em razão de sua doença mental. Tratava-se, portanto, de estabelecer através do exame psiquiátrico se haveria um nexo de causalidade entre o transtorno mental e o cometimento do crime.

Se para o juiz a internação de Sérgio em um HCTP se justificava pelo perigo que o magistrado imaginava que ele ofereceria naquele momento para seus familiares, de acordo com os peritos a probabilidade de que Sérgio voltasse a delinquir em razão de sua saúde mental era baixa. A não equivalência entre o juízo do psiquiatra e do magistrado, nos faz notar a importância de se examinar como elementos morais e emocionais são incorporados na decisão do juiz. Ao ler o processo criminal, a ideia de que Sérgio era perigoso sustentava-se juridicamente pelo relato de que ele produzia medo em seus familiares e nas suas vítimas. $\mathrm{O}$ juiz relatou em sua sentença que o "fetivo perigo do acusado" foi comprovado pelos "tristes e graves relatos

10 Qual seja: “O juiz não ficará adstrito ao laudo, podendo aceitá-lo ou rejeitá-lo, no todo ou em parte." (Brasil 1940:Art. 182) 
das duas vitimas", pelas "investidas" contra a mãe e o irmão que teriam obrigado "a idosa a ausentar-se de sua casa, com medo de seu filho". Em outro fragmento o magistrado descreveu que "Os relatos prestados pelas testemunhas e vitimas dão conta do temor que têm com relação à conduta do réu na localidade", a mãe teria implorado "para que ele fosse internado, ressaltando o temor que tem dele se evadir e voltar a agredi-la".

Para o magistrado devido ao "papel que a justiça deve representar para a sociedade epara as próprias vítimas, evidente que se impõe a medida de internação do acusado". A inimputabilidade de Sérgio mereceria ser reconhecida dada sua "doença mental" e a necessidade de sua internação era justificada com o objetivo de "prevenir condutas mais graves", já que, conforme extraímos da sentença, "o quadro psicológico atestado pelo laudo indica a ocorrência de surtos que levam ao acusado à conduta de extrema periculosidade, independente da vítima”. Apesar do laudo psiquiátrico ter feito a recomendação do tratamento ambulatorial, ao inseri-lo nessas narrativas impregnadas de medo, o juiz desconsidera a indicação psiquiátrica pelo tratamento ambulatorial e utiliza esse mesmo laudo para justificar a necessidade de se internar Sérgio.

Ou seja, na tentativa de dominar aquilo que se desconhece por completo ou parcialmente a causa (por que Sérgio teria feito uma "atrocidade" dessas?) E se teme suas consequências (poderá Sérgio fazer novamente o que já fez no passado?) Nutre-se a esperança no tratamento fármaco-centrado e na internação de Sérgio para que, em tratamento, se cesse a periculosidade do interno fazendo-o menos temível.

\section{b) Cena III: A reinternação de Sérgio}

A antropóloga Janis Jenkins (2011:32) destaca que, frequentemente, os pacientes psiquiátricos experimentam uma "polaridade entre a esperança e o medo" no uso de antipsicóticos: "o medo da hospitalização é a alternativa insuportável, e a esperança pela cura o ideal inatingível” (idem). O tratamento fármaco-centrado promete aos pacientes um "futuro como um self farmacológico medicado por toda vida" ${ }^{11}$. Nesse sentido, a ideia de que o transtorno mental se resumiria a um "cérebro doente", que precisa ser equilibrado, "alimenta a noção do self farmacológico, porque se alguém está morfologicamente 'doente' [sick], necessitará medicar-se constantemente." (ibidem:26).

A relação entre medicamentos e o controle da periculosidade de Sérgio torna-se mais evidente no pedido de sua reinternação feito em fevereiro de 2016, dois meses depois de sua desinternação em dezembro de 2015. Reproduzo a seguir a íntegra do requerimento da reinternação formulado pelo Ministério Público e assinada pela mãe e pelo irmão de Sérgio:

Nesta data, compareceram a esta Promotoria de Justiça a Sra. [nome completo], mãe do apenado, e o Sr. [nome completo], irmão do apenado, declarando que o mesmo foi desinternado em [data]; que morava com ambos em [endereço]; que comparece ao CAPS Y; que no dia [data] teve um surto e expulsou os dois de casa; que tentou agredir um vizinho e o ameaçou; que a mäe desconfia que ele não toma os medicamentos que recebe no CAPS; que o apenado voltou a beber e fumar cigarro; que descumpre os horários estabelecidos para voltar para casa; que não aceita a companbia da mãe nas consultas e idas ao CAPS; que as assistentes sociais e recepcionistas do CAPS disseram que o ape-

11 Jenkins (2011:11), define como pharmaceutical self (self farmacológico) “o aspecto do self orientado por e através das drogas farmacêuticas". 
nado é violento e agressivo com todos; que compareceram à Delegacia, mas não fizeram registro de ocorrência, pois o policial civil falou que o mesmo seria levado ao Presídio e a família deseja que o apenado seja reinternado em Hospital Psiquiátrico. Relatam, ainda, que o apenado está sozinho em casa e não os deixou entrar mais, dizendo que mataria ambos. (Ministério Público, Pedido de Reinternação, grifos meus).

Na certidão do mandado de internação o oficial de justiça relatou que, com o apoio de um batalhão de polícia, deu prosseguimento à reinternação de Sérgio:

O apenado se encontrava sozinho no logradouro e não manifestou violência a internação. No logradouro vizinho se encontrava familiares do mesmo, que presenciaram o ato. Solicitei a medicação do Sr. Sérgio, a sua mãe, Sra [nome]. A última, após entrar na residência onde se encontrava ofilho, informou que a medicação não se encontrava junto aos seus pertences, e, que, provavelmente o mesmo jogou fora. Dei ciência aos familiares presentes, que, o apenado seria conduzido por mim até o [HCTP-X], por ordem continua do juiz da VEP [Vara de Execuções Penais]. Aproximadamente às $14 ; 15 \mathrm{~h}[\mathrm{sic}]$, apresentei o apenado ao citado hospital prisional, o qual foi recebido pelo funcionário [nome] que já se encontrava ciente da presente internação. (Oficial de justiça. Fragmento do Mandado de Reinternação, grifos meus).

Nos dois trechos anteriormente destacados, podemos depreender que a falta de medicamentos no corpo de Sérgio é percebida como a causa de seu comportamento violento ou, ao menos, como podemos verificar pela solicitação do medicamento feita pelo oficial de justiça e a acusação materna de que o rapaz teria se livrado dos remédios, os psicotrópicos parecem ser moralmente devidos e qualquer índice de sua não utilização indicaria um desvio moral de Sérgio, mesmo que ele não tenha manifestado "violência a internação", i.e., resistência à prisão. Ao contrário de outras drogas (como o tabaco ou a bebida alcoólica), os psicotrópicos assumem, neste contexto, um valor moral positivo e um grande efeito de controle.

Os textos legais que documentam a internação e reinternação do Sérgio tal qual descreve Scaramella (2015:201): "arquivam essa vida e, na medida em que o fazem, resgatam e contrapõem elementos da mesma, escolhidos de acordo com uma intenção que não foge ao biográfico e que levará em direção à culpa ou à inocência”. Estes documentos não apenas confeccionam a biografia institucional de Sérgio, mas também performam materialidades e produzem efeitos específicos no corpo do condenado. Por isso mesmo todas as acusações de indisciplina do Sérgio são traduzidas oficialmente como manifestações patológicas de seu comportamento desviante. Tradução essa que, em última instância, fundamenta a necessidade da (re)internação e consequente adesão do paciente ao tratamento-compulsório da medida de segurança, cuja qualidade maior seria a de conseguir estabilizá-lo psiquiatricamente. Para melhor compreender o que caracteriza essa "estabilização" retornaremos ao período da desinternação do Sérgio, isto é, ao momento anterior a sua reinternação.

Todos os relatos terapêutico-legais precedentes ao conflito familiar que deram origem à reinternação de Sérgio (quando ele ainda se encontrava internado pela primeira vez no Hospital de Custódia) decidiram que a internação de Sérgio era desnecessária. Os diferentes pareceres que apontaram para a 
desinternação do paciente afirmavam que ele tinha estabelecido um bom vínculo familiar e fazia uso contínuo do medicamento.

Nos documentos em que se pediu o benefício da Saída Terapêutica para Sérgio (através de sua concessão o paciente poderia passar um período de tempo fora do manicômio), bem como nos pareceres que requisitavam sua desinternação, ele era apresentado como: "estabilizado do ponto de vista emocional" ou "estabilizado do ponto de vista psiquiátrico". O laudo de cessação de periculosidade do perito informava: Sérgio "apresenta-se com um quadro psiquiátrico estabilizado no momento sem periculosidade, condiçôes de ser desinternado, devendo ter apoio de responsável e dar continuidade ao tratamento de saúde mental a nivel ambulatorial". É ressaltado que Sérgio "participa das atividades junto à familia", como previa seu "projeto terapêutico" dentro da instituição, cujo objetivo era: "manter o paciente estabilizado do ponto de vista psiquiátrico e realizar saidas terapêuticas que venham a manter o vinculo familiar". Diferentes pareceres destacam que se Sérgio fosse desinternado seria "dada a continuidade do projeto terapêutico através do acompanhamento ambulatorial após a inserção do paciente no CAPS Z" ou como destacou o perito: para ser desinternado Sérgio deveria "ter apoio de responsável e dar continuidade ao tratamento de saúde mental a nivel ambulatorial".

Como parece sintetizar bem o laudo psiquiátrico que concedeu a cessação de periculosidade, exposto anteriormente, dois elementos são colocados como simetricamente essenciais para garantir a estabilidade emocional-psiquiátrica de Sérgio e, consequentemente, a cessação de sua "periculosidade": "uso contínuo da medicação" e "visitas regulares da mãe". Embora muitas vezes esses critérios apareçam no discurso dos atores como dois elementos distintos, eu diria que não só eles são interdependentes, como o uso contínuo do medicamento é visto como central para a efetivação da saída do paciente da instituição e para que ele possa conviver bem com os familiares. Os casos divergentes, aqueles em que se interpreta que o interno resiste ao tratamento e/ou não tem família para recebê-lo são considerados, pelos trabalhadores do HCTP, como "casos difíceis".

Até mesmo na audiência de desinternação de Sérgio a centralidade do medicamento foi mencionada em conjunto com o testemunho da correção moral de Sérgio neste período. Nessa audiência foi dito que o desinternante era trabalhador, não usava drogas ilícitas e estava predisposto a dar continuação ao tratamento fora do manicômio. A adesão do desinternante ao tratamento extramanicomial oferece as “condições para o reconhecimento" (Butler 2015:19)12 de Sérgio (ou de qualquer outro interno) como um sujeito moralmente responsável e bioquimicamente estabilizado. É este testemunho moral que lemos na assentada da audiência de desinternação:

Pela representante da Equipe Técnica foi dito que: o paciente é muito tranquilo; que usa medicação regularmente; que nunca deu problema; [...]; que o apenado não tem problema com drogas; que o apenado ficará com a mãe [...] que o paciente é interditado. Pelo paciente foi dito: que já foi no CAPS conhecer e que afirmaram que o acompanhamento iniciaria após a desinternação;

12 Butler (2015: 19) define "condições para reconhecimento" como "as condições gerais que preparam ou modelam um sujeito para o reconhecimento - os termos, as convenções e as normais gerais 'atuam' do seu próprio modo, moldando um ser vivo em um sujeito reconhecível, embora não sem fabilidade ou, na verdade, resultados não previstos" elas "precedem e tornam possível o ato do reconhecimento propriamente dito". 
que é serralheiro e deseja voltar a trabalhar como profissional liberal; que já trabalhou com carteira assinada. Pela mãe do interno foi dito que: Tem condições e deseja recebe-lo em sua casa; que seu filho mais velho também está morando com a depoente. (Juíza, Fragmento da Assentada da Audiência de Desinternação de Sérgio, grifos no original).

Por fim, entre outras recomendações disciplinares, no final do documento reiterou-se que Sérgio era obrigado a "submeter-se a tratamento ambulatorial no CAPS Z".

O efeito central das balizes terapêutico-legais vistas anteriormente é a configuração e instituição do medicamento como mediador técnico (Latour,1994) do controle/cuidado de Sérgio. Ao observarmos a ênfase dada ao medicamento pelos diferentes atores que compõem sua rede de assistência e vigilância (sua mãe, irmão, defensora pública, promotor, psiquiatra, psicóloga, assistente social...), nós podemos notar que aos medicamentos são atribuídos os efeitos simbólicos e materiais da contenção do espírito agressivo de Sérgio em seu corpo sedado.

À sua família resta exercer o papel de "agente médico do Estado" (Biehl 2008:440), pois, como muitas outras famílias de usuários de serviços de saúde mental, é ela quem "faz a triagem dos cuidados e tratamento" do familiar "doente" (idem). O pedido de reinternação de Sérgio feito por seus familiares ilustra o fenômeno que o antropólogo João Biehl (2008) relatou. De acordo com o autor muitas vezes as famílias aprendem a agir como “"proxy-psychiatrists' ou psiquiatras de fundo de quintal, podendo se livrar de seus membros improdutivos e indesejados, às vezes sem sanção, baseado no fato de que tais indivíduos não se submetem aos regimes de tratamento" (idem).

O psicotrópico prescrito e regulado como medicamento é, portanto, uma "tecnologia moral" (Biehl 2008:440) fundada sobre seu estatuto inequívoco de verdade científica para os múltiplos atores envolvidos com o paciente (Biehl 2008, 2011). Desse status deriva concomitantemente a noção da concretude do fármaco enquanto "coisa" e sua maior fluidez em relação ao controle médico restrito, pois o medicamento é simultaneamente "a extensão do médico" (Sjaak; Whyte 2011:468) e a libertação do paciente de suas mãos (idem). Os remédios psiquiátricos permitem ao mesmo tempo a vigilância e cuidado por parte da família sobre o corpo do paciente e o controle biopolítico das instituições estatais (HCTP, CAPS, Judiciário) da adesão e continuidade do tratamento do desinternado. Todavia, precisamos notar que as tentativas de integração ou reintegração do paciente à rede de saúde mental fogem, muitas vezes, das previsões normativas da política pública ou do pensamento biomédico e são remodeladas criativamente pelas situações e atores concretos (Bonet 2014).

\section{A microbioquímica do poder}

A centralidade do uso do medicamento na medida de segurança não é um argumento exclusivamente acusatório utilizado apenas pelo Ministério Público, família ou pela equipe de saúde responsável pelo caso de Sérgio. A própria defesa do paciente enfatizou o uso do medicamento como um dos con- 
tra-argumentos centrais para impedir juridicamente sua reinternação. Nesta peça, a defensora rebatia os argumentos de que Sérgio não estava se tratando:

a medicação do Sérgio é INJETÁVEL. Por isso não foi encontrada em sua residência. E mais, nele foi ministrada na véspera da sua prisão, razão pela qual estava muito sonolento e sem esboçar resistência alguma, conforme deflui da certidão [emitida pelo Oficial de Justiça]. (Defensora pública, Peça de Defesa, grifos no original)

A invisibilidade da droga, especialmente aos olhos dos trabalhadores do setor jurídico que não a via sendo aplicada ou ingerida pelos pacientes, mas presenciava seus efeitos nos corpos dos internos, revela uma certa microbioquímica ou "microfísica do poder" (Foucault 2010a:134) dos medicamentos, i.e. um conjunto de técnicas que "definem um certo modo de investimento político e detalhado do corpo" (idem). Por exemplo, em um atendimento, com outro paciente, ao perceber que um interno tremia a defensora lhe perguntou: "tá com frio?" Ele respondeu "não, é que eu fico tremendo mesmo". Quando o paciente saiu da sala, a jurista questionou imediatamente a psicóloga que acompanhava a cena: "por que ele treme tanto?" Ela lhe respondeu: "o Dr. Silva mudou a medicação. Não sei se é falta de medicação ou é a medicação nova".

A invisibilidade do medicamento quando incorporado pelo paciente promove uma fusão entre os efeitos colaterais da ingestão de substâncias químicas no corpo do paciente com suas expressões próprias, reforçando a abjeção (simbólica e material) do corpo-louco. Como afirma Judith Butler em entrevista "o abjeto [...]. Relaciona-se a todo tipo de corpos cujas vidas não são consideradas 'vidas' e cuja materialidade é entendida como 'não importante." (Prins; Meijer 2002:161). Nesse sentido, o corpo abjeto não seria passível de inteligibilidade ontológica, dessa forma a sua materialidade é circunscrita - em termos de efeitos de poder - por certos saberes e práticas que procurariam controlá-los e defini-los de acordo com um ideal de normatividade e normalidade (Butler 2000; Foucault 2010b). Sendo assim, realiza-se uma passagem do tremor como efeito de uma causa externa (tal qual imaginado pela defensora) a um status vital ("fico tremendo mesmo"). Seja pela "falta de medicação" ou "pela medicação nova" o remédio é concebido como referência para descrever o comportamento do interno. Se, no manicômio, qualquer expressão do louco só pode ser parte da sua loucura, também os efeitos corporais do medicamento são englobados como manifestações patológicas.

Como vimos no caso de Sérgio, se o psicotrópico é capaz de contornar a periculosidade do louco-criminoso, fazendo com que ele não esboce "resistência alguma", como disse a defensora, isto se dá a partir da hipermedicalização de seu corpo e a farmacologização de sua subjetividade.

Em um de seus atendimentos jurídicos, quando perguntado especificamente sobre o uso de medicamentos Sérgio respondeu: "na quarta me deram uma injeção e um monte de remédio", ele também teria relatado não sem alguma angústia que "o CAPS tá sem remédio [...]. Eu falei no CAPS que tava sem remédio e lá não me aceitaram [...] e me mandaram para o CAPS Z, lá falei que tava sem remédio...”.

A dificuldade de relacionamento com o irmão e com a mãe somada à resistência ao acolhimento de Sérgio pelo CAPS produziram uma nova narrativa sobre o rapaz, pela qual ele se encontraria à deriva, 
em um estado de liminaridade (Turner 1974) social e biopsíquica. Este estado liminar parece fortalecer-se pela "falta de medicamentos" que "desequilibraria" não somente Sérgio, mas a toda rede de cuidado/ controle responsável por ele.

\section{Considerações finais}

A maior ênfase no tratamento medicamentoso em relação à terapia psicossocial transforma a medida de segurança em uma verdadeira experimentação farmacológica. Aliás, esse fenômeno não se restringe ao manicômio judiciário, mas engloba a rede de saúde mental como um todo. O Brasil ocupa o sexto lugar no mercado farmacêutico mundial. O que torna esse dado ainda mais significativo é que o país adota um modelo de saúde (geral e mental) centralizado na prescrição e consumo em larga escala de medicamentos. No ano de 2012 o mercado farmacêutico brasileiro chegou a movimentar 28,5 bilhões de dólares (Matos 2014).

A abordagem fármaco-centrada da loucura representaria um modelo de assistência em saúde mental mais viável economicamente para o Estado brasileiro desde os anos 90, como afirma João Biehl (2007:403-404):

A distribuição gratuita de medicamentos (incluindo psicofarmacêuticos) é um componente central na busca do Brasil por um sistema de saúde universal que seja economicamente viável. Dada as reformas neoliberais no país, a importação de drogas aumentou substancialmente em meados dos anos 90 [...]. A farmacologização da saúde pública corre em paralelo com a descentralização e desaparecimento geral das infraestruturas clínicas.

Apesar das significativas mudanças geradas pela Lei da Reforma Psiquiátrica (Lei 10.216/2001) que possibilitou o surgimento de dispositivos com uma abordagem mais psicossocial da loucura, ainda há a prática de prescrição excessiva de medicamentos para os usuários dos serviços de saúde mental (Ferrazza et al, 2013). Desde a reforma, a política pública nessa área tende a diminuir os gastos hospitalares e aumentar os gastos extra-hospitalares, tendência esta que está se invertendo a partir da gestão do governo Bolsonaro em 2019 (Brasil 2018, Pinheiro 2019). Com a reforma psiquiátrica houve o decréscimo do número de hospitais psiquiátricos e a criação de dispositivos substitutivos, como os CAPS, aumentou-se o gasto com medicamentos, concebidos pela política pública como fundamentais para evitar as crises psiquiátricas que levariam a internação dos usuários nos hospitais. Essa conjuntura, portanto, torna a questão da distribuição e acesso dos psicotrópicos significativa para a gestão estatal dessa parcela da população (Brasil 2004; Gonçalves et al 2012; Mateus et al 2013).

O HCTP se inscreve no circuito farmacológico que percorre tanto a rede de saúde mental, quanto o sistema de justiça criminal. A “estabilização psiquiátrica” é a condição para a responsabilização moral do paciente por seu tratamento: o dano que ele cometeu (a si mesmo e/ou aos outros) passaria a ser compreendido como manifestação de sua doença, a qual o paciente deve tornar controlável pela adesão ao tratamento. Se por um lado a medida de segurança é concebida como a alternativa jurídica para os inimputáveis, portanto "irresponsáveis" pelos seus atos. Por outro, o tratamento não deixa de imputar 
uma pena, mas inscreve as práticas de punição e responsabilização no estilo terapêutico. O poder punitivo no manicômio judiciário é atuante, porém se apresenta por um "envoltório psicossocial de diagnóstico e cura" (Garland 2005:279).

O objeto do tratamento-compulsório, “a doença mental” mesclada como a "periculosidade”, é correlacionado ao próprio psicotrópico que o operacionaliza. O medicamento implica em uma cartografia do corpo, imprime certas intensidades e traça, por contraste, sua versão extensiva, mórbida, uma doença que é o seu duplo, como a molécula de serotonina é para a depressão: "Uma molécula só é um marcador biológico, porque ela desenha, em negativo, um mecanismo biológico." (Pignarre 1999:124). A medicalização da periculosidade produz a doença e o tratamento do louco-criminoso.

Sob o "equilíbrio psiquiátrico" corre uma volátil relação entre os internos e o tratamento medicamentoso no HCTP. Ao destacar isso talvez nos deparamos com um dos maiores, senão o maior paradoxo do uso e abuso dos psicotrópicos no tratamento dos incriminados que cumprem a medida de segurança. Se o objetivo último da máquina terapêutico-legal do manicômio judiciário é "fazer cessar a periculosidade" do interno, os medicamentos podem não ser os meios mais eficazes para isso. Ora, o uso prolongado dos psicofármacos pode apresentar, dentre outros "sintomas habituais" a "instabilidade emocional com irritabilidade e ataques de ira" (Gøtzsche 2016:270) ${ }^{13}$. A própria possibilidade do efeito colateral do psicotrópico ser o oposto simétrico ao que pretende os que creem na medicalização da periculosidade já coloca em questão a qualidade do tratamento da medida de segurança especialmente e da rede de saúde mental como um todo. No entanto, o fortalecimento e integração dos dispositivos de internação à Rede de Atenção Psicossocial (RAPS), o desmonte de programas alternativos na área, como a redução de danos, a incorporação das comunidades terapêuticas pela gestão pública ou o estímulo de "tratamentos" não-medicamentosos, como o eletrochoque (Pinheiro 2019, Brasil 2018 e 2019) se apresentam no cenário político contemporâneo como falsas alternativas à ineficácia do tratamento fármaco-centrado que apenas justificam o maior controle e gestão deste segmento populacional e não o cuidado. Enquanto não nos depararmos criticamente com a concepção de "doença mental” que sustenta a ideologia do equilíbrio químico superestimaremos a eficácia dos medicamentos e reificaremos a patologia mental em um bloco natural, sem concebermos seus enredamentos biopsicossociais.

Túlio Maia Franco é doutorando em Antropologia Cultural pelo Programa de Pós-Graduação em Sociologia e Antropologia da Universidade Federal do Rio de Janeiro (PPGSA/UFRJ) e bolsista do CNPq. Mestre em Sociologia (com concentração em Antropologia) pelo PPGSA/UFRJ. Membro do Laboratório de Etnografias e Interfaces do Conbecimento (LEIC/UFRJ).

13 Para mais informações conferir a revisão feita por Peter Gøtzsche (2016) sobre os efeitos colatareis dos psicofármacos, dentre eles sua relação com o aumento da agressividade dos consumidores. 


\section{REFERÊNCIAS BIBLIOGRÁFICAS}

BIEHL, João. 2007. A Life: Between Psychiatric Drugs and Social Abandonment. In: BIEHL, João, GOOD, Byron e KLEINMAN, Arthur (orgs.). 2007. Subjectivity: ethnographic investigations. Berkley: University of California Press.

.2008. “Antropologia do devir: psicofármacos - abandono social - desejo”. Revista de Antropologia, v.51, n. 2:413-449,.

2011. “CATKINE ... Asylum, Laboratory, Pharmacy, Pharmacist, I and the Cure: Pharmaceutical Subjectivity in the Global South.” In: JENKINS, Janis (org). Pharmaceutical Self and Imaginary: Psychopharmacology in a Globalizing World. Santa Fe: SAR Press. BONET, Octavio. 2014. Itinerações e malhas para pensar os itinerários de cuidado: A propósito de Tim Ingold. Revista sociologia \& antropologia. Rio de janeiro, v.4, n.2:327-350.

BRASIL. 2004. Conselho Nacional de Secretários de Saúde. Para entender a gestão do Programa de Medicamentos de dispensação em caráter excepcional. Brasília: CONASS.

Decreto-lei 2848 de 7 de dezembro de 1940.Código Penal. Disponível em: < http://www. planalto.gov.br/ccivil_03/decreto-lei/Del2848compilado.htm>. Acesso em 28 de abril de 2017. . Lei no 7.210 de julho de 1984.Lei de Execução Penal. Disponível em: <http://www.planalto.gov.br/ccivil_03/leis/L7210.htm>. Acesso em: 27/03/17.

. Lei 10.216 de 06 de abril 2001. Lei da Reforma Psiquiátrica. Disponível em: < http://www. planalto.gov.br/ccivil_03/leis/leis_2001/110216.htm>. Acesso em 28 de abril de 2017.

. Política Nacional de Saúde Mental, Álcool e Outras Drogas. Ministério da Saúde. Disponível em: <http://portalms.saude.gov.br/politica-nacional-de-saude-mental-alcool-e-outras-drogas >. Acessado em 01 de maio de 2019.

Decreto $\mathrm{n}^{\circ} 9.761$ de 11 de abril de 2019. Aprova a Política Nacional sobre Drogas.

Disponível em:<http://www.in.gov.br/materia/-/asset_publisher/Kujrw0TZC2Mb/content/ id/71137357>. Acesso em 01 de maio de 2019.

BUTLER, Judith. 2015. Quadros de guerra: quando a vida é passível de luto? Rio de Janeiro: Civilização Brasileira.

.2000. Corpos que pesam: sobre os limites discursivos do sexo. Tradução de Tomaz Tadeu da Silva. In: LOURO, Guacira Lopes (Org.), O corpo educado, $2^{\text {a }}$ edição. Belo Horizonte: Autêntica. FERRAZZA, Daniele et al. 2013. Medicalização em um serviço público de saúde mental: um estudo sobre a prescrição de psicofármacos. Gerais, Rev. Interinst. Psicol., vol.6, n.2:255-265.

FOUCAULT, Michel. 1988. 'Technologies of the self. In: MARTIN, L. H., et al. (org.). Technologies of the Self: A seminar with Michel Foucault. Amherst: The University of Massachusetts Press.

.2006. O Poder Psiquiátrico: curso dado no Collège de France (1973-1974). São Paulo: Martins Fontes.

2010a. Vigiar e Punir: nascimento da prisão. 38 a ed. Petrópolis: Vozes.

.2010b. Os Anormais: curso no Collège de France (1974 - 1975). $2^{\text {a }}$ Edição. São Paulo:

Martins Fontes. 
FRANCO, Túlio Maia. 2017. Além da medida: uma etnografia do "tratamento" previsto na medida de segurança em um manicômio judiciário do Estado do Rio de Janeiro. Dissertação (Mestrado em Sociologia e Antropologia) - Programa de Pós-Graduação em Sociologia e Antropologia, Rio de Janeiro: Universidade Federal do Rio de Janeiro.

GARLAND, David. 2005. Cultura del control: crimen y orden social em la sociedade contemporánea. Barcelona: Editorial Gedisa.

GOFFMAN, Erving. 1974. Manicômios, prisóes e conventos. São Paulo: Perspectiva, 1974.

GONÇALVES, Renata Weber; VIEIRA, Fabíola Sulpino; DELGADO, Pedro Gabriel Godinho. 2012. Política de Saúde Mental no Brasil: evolução do gasto federal entre 2001 e 2009. Rev. Saúde Pública, São Paulo, v. 46, n. 1:51-58.

GØTZSCHE, Peter. 2016. Psicofármacos que matan y denegación organizada, Barcelona: Los Libros del Lince.

HARAWAY, Donna. 1997.Modest-Witness@Second-Millennium.FemaleMan@-Meets-OncoMou$s e^{\text {twi }}$ : feminism and technoscience. New York: Routledge.

INGOLD, Tim. 2012.Trazendo as coisas de volta à vida: emaranhados criativos num mundo de materiais. Horiz. antropol., Porto Alegre, v. 18, n. 37:25-44.

IRIART, Celia; MERHY, Emerson.2017. Disputas inter-capitalistas, biomedicalización y modelo médico hegemónico. Interface, v. 1:1-18.

JENKINS, Janis. 2011. Psychopharmaceutical Self and Imaginary in the Social Field of Psychiatric Treatment, In: (org) Pharmaceutical Self and Imaginary: Psychopharmacology in a Globalizing World. Santa Fe: SAR Press.

KESSING, Lars, et al. 2005. Depressive and bipolar disorders: patients' attitudes and beliefs towards depression and antidepressants. Psychol Med, v. 35: 1205-1213.

LATOUR, Bruno. 1994. On technical mediation - philosophy, sociology, genealogy. Common Knowledge, v.3, n. 2:29-64.

LEADER, Darian.2015. Simplesmente bipolar. Rio de Janeiro: Zahar.

MATEUS, Mário. 2013. Politicas de saúde mental: baseado no curso Políticas públicas de saúde mental, do CAPS Luiz R. Cerqueira. São Paulo: Instituto de Saúde.

MATOS, Alexandre. 2014. Grupo faz mapeamento da farmoquímica nacional. Agência fiocruz de notícias. Rio de Janeiro, 21 de mar. de 2014. Disponível em: < https://agencia.fiocruz.br/grupo-faz-mapeamento-da-farmoqu\%C3\%ADmica-nacional>. Acesso em: 18 fev. 2019.

MISSE, Michel. 2010. Crime, sujeito e sujeição criminal: aspectos de uma contribuição analítica sobre a categoria "bandido". Lua Nova, n. 79:15-38.

MITJAVILA, Myriam; MATHES, Priscilla. 2016. Labirintos da medicalização do crime. Saúde soc., v.25, n.4: 847-856.

MITJAVILA, Myriam; VÁSQUEZ, María. 2018. Apresentação - Medicalização do crime: indagações genealógicas. Saúde soc. v.27, n.2:295-297.

PERES, Maria Fernanda Tourinho; NERY FILHO, Antônio. 2002. A doença mental no direito penal brasileiro: inimputabilidade, irresponsabilidade, periculosidade e medida de segurança. Hist. 
cienc. saude-Manguinhos, v.9, n.2:335-355.

PIGNARRE, Philippe. 1999. O que é o medicamento?: um objeto estranho entre ciência, mercado e sociedade. São Paulo: Editora 34.

PRINS, Baukje; MEIJER, Irene Costera. 2002. Como os corpos se tornam matéria: entrevista com Judith Butler. Rev. Estud. Fem., v..10, n.1:155-167.

ROSE, Nikolas. 2013. A politica da própria vida: biomedicina, poder e subjetividade no Século XXI. São Paulo: Paulus.

SAFATLE, Vladimir. 2015. O circuito dos afetos: corpos políticos, desamparo e o fim do indivíduo.

São Paulo: Cosac Naify.

SCARAMELLA, Maria Luisa. 2015. Biografias judiciárias: analisando laudos psiquiátricos de autos de processos penais. In: KOFES, Suely; MANICA, Daniela (orgs.) Vidas \& Grafias: narrativas antropológicas entre biografia e etnografia. Rio de Janeiro: Lamparina Editora.

SJAAK, Van Der Geest; WHYTE, Susan Reynolds. 2011. O encanto dos medicamentos: metáforas e metonímias. Sociedade e Cultura, v. 14, n. 2:457-472.

TURNER, Victor. 1974. O Processo Ritual: Estrutura e Anti-Estrutura. Petrópolis: Vozes. 


\section{“O COMPRIMIDO ENTRA E O CHIP SAI”: UMA ANÁLISE ETNOGRÁFICA DA ME- DiCALIZAÇÃo da PERICULOSIDADE EM UM MANICÔMIO JUDICIÁRIO}

Resumo: Neste artigo descrevo o papel central que ocupam os psicotrópicos no tratamento-compulsório do manicômio judiciário. Para explorar esta questão analiso, em um primeiro momento, uma série de documentos jurídicos e administrativos que versavam sobre o déficit no estoque de medicamentos e seus efeitos negativos sobre a população de internos nos dois Hospitais de Custódia e Tratamento Psiquiátrico (HCTP) do Estado do Rio de Janeiro. Na segunda parte do texto examino etnograficamente a história de Sérgio, paciente de um HCTP que foi reinternado na instituição poucos meses após extinta sua medida de segurança. A análise antropológica do caso de Sérgio permitirá melhor compreender de que modo a "medicalização da periculosidade" se relaciona com a ideia de que o tratamento medicamentoso seria capaz de restituir o "equilíbrio psiquiátrico" ao paciente fazendo cessar sua "periculosidade".

Palavras-chave: Medicalização, Periculosidade Criminal, Manicômio Judiciário, HCTP, Medida de Segurança

\section{“PILL IN, CHIP OUT": AN ETNOGRAPHIC ACCOUNT OF DANGEROUSNESS MEDI- CALIZATION AT A FORENSIC PSYCHIATRIC HOSPITAL}

Abstract: In this article I describe the major role played by psychotropics in the compulsory treatment that takes place at forensic psychiatric hospitals. To explore this question first I analyze several legal and administrative documents about a deficit on the medicine stock and its negative effects on the inmate population of two forensics psychiatric hospitals of Rio de Janeiro state's. In the second part of this article I offer an ethnographic account of Sérgio, a patient that was reincarcerated just a few months after his mandatory custody extinction. The anthropological analysis of Sérgio's case give us a better comprehension on how the "medicalization of dangerousness" relates with the idea that the pharmacological treatment would be able to recover the "psychiatric equilibrium" of a patient stopping his "dangerousness".

Keywords: Medicalization, Criminal Dangerousness, Forensic Psychiatric Hospital, HCTP, Mandatory Custody

RECEBIDO: $20 / 02 / 2019$

APROVADO: $02 / 05 / 2019$ 